\title{
When Zero-Sum Yields No Winners: The Case of Implementing Changes To Bilingual Education Law In Massachusetts
}

\section{By Nicholas Lee}

Abstract: Even when clear outcomes arise from a political process, corresponding victories and defeats are not always translated into an implementation reality. The case of implementing recent changes to bilingual education law in Massachusetts serves as an apt example of such a phenomenon. In particular, two crucial educational implementation factors, perceived policy legitimacy and teacher motivation, and their interplay, will be analyzed vis-à-vis the policy approval and implementation processes. The methodology of this presentation will include both a direct analysis of Massachusetts'situation and a comparative one with the more developed implementation process in California. From these analyses, possible implementation outcomes within Massachusetts will be presented along with suitable recommendations for spurring positive movement within the implementation process.

\section{INTRODUCTION}

The story of bilingual education in Massachusetts highlights the all too common disconnect between political decision making and actual policy implementation. In 2002, following a contentious political battle, Massachusetts approved a proposal to change its bilingual education policy. The new policy will be implemented during the 2003-2004 academic year and will require the state to face the challenges that arise during implementation. While the political process produced very clear winners and losers in this debate, the amount of energy, resources, and time needed to transform this political outcome into a policy

Nicholas Lee is a 2004 graduate of the Master of Public Administration program at The George Washington University, holding dual concentrations in education policy implementation and federal policy management. He obtained his Bachelor degree in economics and international relations from Boston University in 2001. Currently, he is employed by the U.S. Department of Education as a Management and Program Analyst working with postsecondary and higher education issues. He hails from Northboro, Massachusetts and can be contacted at Nicholas.Lee@ed.gov.

The author particularly wishes to thank MS. Katherine France and Dr. Yas Nakib for their invaluable assistance on this article. reality may end up being far greater than originally anticipated.

This article seeks to analyze the factors that may influence the implementation of these changes to Massachusetts' bilingual education laws and makes predictions about the future of these new policies. While there are numerous factors that can affect policy implementation, the issues of policy legitimacy and teacher motivation will be at the heart of this analysis. As a point of comparison, the recent implementation of bilingual education reforms in California will be used as a model for making further inferences about what lies ahead for bilingual education in Massachusetts. Despite the fundamental differences between the two states, the experience of California's reforms provides many valuable analytical points not only in predicting, but also improving, the implementation process in Massachusetts.

As mentioned above, the concepts of policy legitimacy and teacher motivation frame this case study of Massachusetts' bilingual education reforms. The public perception of how necessary bilingual education reform was, how effective it could be, and how it came to be approved are all central to the process of implementation. The way that stakeholders, including politicians, education officials, teachers, and parents, understand these issues will likely have a significant effect on the implementation process. 
While teacher perception of the legitimacy of reform is important, the substance of reform must also be implemented in classrooms with new practices and pedagogies. The second factor influencing implementation, teacher motivation, focuses on the "street-level bureaucrats" charged with policy implementation (Lipsky 1997, 401). Simply stated, the presence or absence of motivated teachers will shape the ways in which policy implementation will proceed. Availability of resources, the ability to exercise professional judgment, and teachers' personal feelings about the new reforms are only a few of the factors that can influence teacher motivation and guide the way that teachers choose to implement, or not to implement, such policy changes.

Perhaps most important to note here is that these two-teacher perception of the legitimacy of the policy and teacher motivation-are not mutually exclusive. In fact, all of the events and issues discussed throughout this article can affect either one or perhaps both of these concepts. Therefore, in examining a particular issue, the lenses of policy legitimacy and teacher motivation are used separately and collectively in order to obtain a clearer picture of the complex nature of bilingual education policy implementation in Massachusetts.

\section{Bilingual Education in Massachusetts since 1971}

For the twenty-five years prior to November 2002, bilingual education law in Massachusetts had remained relatively untouched. Written in 1971, Massachusetts General Law Chapter 71A established standards for providing transitional bilingual education (TBE) to cities and towns within the Commonwealth. In fact, Massachusetts was the first state to mandate the provision of these services to students who are deficient in the English language. TBE programs seek to utilize and develop linguistic competence in a student's native language as a foundation for academic and linguistic development in English. While it is the goal of these programs to eventually place these students into mainstream classrooms, the benefit of native language instruction, particularly at the early stages, is recognized as well (Mitchell et al. 1999).

The 1971 law stipulated that local school districts were to provide TBE programs when twenty or more students in the district spoke the same non-English native language. Students would be placed in these programs for three years at which point their English fluency would be evaluated. If it was determined that a student did not possess sufficient English skills, he or she would remain in the bilingual program pending further evaluation of his or her English language development. Should the number of students speaking a native language other than English fall under twenty at any time, school districts were required to provide some form of linguistic support but the kind of support was not stipulated.

Bilingual education in Massachusetts continued in this way for nearly twenty-five years. Throughout the 1990's and into the early part of 2000, these programs served roughly 30,000 to 40,000 students each year (about 3-4.5 percent of the entire student population) and remained unchanged by the legislature (Massachusetts Board of Education 2003). However, over that time period, policies on bilingual education did come under increased scrutiny. As part of the Education Reform Act of 1993, the Massachusetts legislature called for an assessment of the effectiveness of these programs. Two groups, the Pioneer Institute of Public Policy and the Massachusetts Bilingual Education Commission, were assigned this evaluation. Unfortunately, little conclusive information was discovered. Both studies identified a significant lack of student performance data within school districts. The report by the Bilingual Education Commission stated that, "despite TBE being in place in Massachusetts for 23 years, we don't know whether it is effective...There are no comprehensive data that evaluate the performance of TBE pupils compared with pupils from other groups" (Massachusetts Bilingual Education Commission 1993). Since there was no state requirement for data collection by these TBE programs, researchers were unable to conduct any rigorous scientific evaluations.

Instead, both studies offered broad observations, based largely on conjecture, about the state of bilingual education within Massachusetts. Of particular interest to this article, the author of the Pioneer Institute study wrote that:

Massachusetts is unjustified in going way above and beyond the federal government 
and other states, in not only requiring a fulltime program...but in requiring it if there are 20 Limited English Proficiency students of a single language group in that school district-the equivalent of only one or two students per grade. (Rossell 1996)

The Pioneer Institute study argued that Massachusetts, by exceeding federal standards, was inefficiently utilizing resources to educate a potentially small segment of school district populations. The study advocated changing the law to relieve an undue burden on local school districts. Meanwhile, the Bilingual Education Commission, by contrast, arrived at the conclusion that continued improvement and increased funding of bilingual programs was valuable for future educational performance.

In response to these limited findings and based on their personal views on the issue, Massachusetts political figures moved into action. Governor William Weld, a Republican, filed a bill that changed the number of students triggering special language classes and required schools to instruct all non-native English speakers, regardless of native language, in the same classroom. He also proposed that such programs be completed in one year instead of three. Meanwhile, Democratic proposals sought to alter other items such as teacher certification standards. The partisan debate that ensued in the largely Democratic state legislature was merely a preview of the debate that would soon envelop the entire state. The work of Massachusetts' legislators would soon be overshadowed by an unexpected but extremely powerful political movement.

\section{The RoAd to Immersion}

On July $31^{\text {st }}, 2001$, a petition for a ballot initiative was filed with and accepted by the Massachusetts Attorney General's Office. Filed by Lincoln Tamayo and co-sponsored by eighteen other Massachusetts residents (including the author of the Pioneer Institute report, Christine Rossell), the petitioners wished to change dramatically the existing laws governing bilingual education programs. This petition was part of a nationwide effort led by California native and Silicon Valley tycoon Ron Unz. By filing ballot petitions in states throughout the country, he and his supporters sought to replace TBE programs with structured English immersion (SEI) programs.

Unlike TBE, SEI programs are grounded in the pedagogical belief that "the most efficient path to both English-language development and academic achievement is through the use of the majority language, English" (Mitchell et al. 1999, 94). Rather than utilizing a student's native language development as a tool for academic and linguistic development in English, this teaching methodology regards a student's native language as a source of interference in English language development. Classroom time focuses on quickly mainstreaming students by "immersing" them in primarily English-based instruction with minimal translation support.

Drawing from the theory of SEI, the statutory language proposed by Tamayo and his co-petitioners suggested drastic changes to existing law. The first notable difference between the existing and proposed systems was the timeframe. Section Four of the ballot initiative required that English immersion be conducted, "during a temporary transition period not normally intended to exceed one school year." In addition to a change in the timeframe during which bilingual education would occur, elimination of the requirement for TBE programs based upon the number of non-English students per district was proposed. Linked to this proposal was the suggestion that "local schools shall be encouraged to mix together in the same classroom English learners from different nativelanguage groups but with the same degree of English fluency" (Office of the Attorney General of the Commonwealth of Massachusetts 2001). This proposal emphasized the belief of SEI supporters that a student's native language ability should not be a consideration in the development of English skills. By combining classes of non-native students, the proposal offered the potential benefit of allocating teaching resources more efficiently, addressing one of the concerns expressed by the Pioneer Institute. Finally, and perhaps most notably, these new provisions would be backed up with enforcement procedures not included in previous legislation.

The choice was placed before Massachusetts' voters as Question 2 on the November 2002 ballot. Leading up to this historic vote, numerous stakeholders mobilized their supporters. All of the state educational 
interest groups representing teachers and school administrators, along with minority groups, particularly from Latino backgrounds, joined to oppose Question 2. The efforts of state-based opponents captured the attention of national groups including the National Association for Bilingual Education. Meanwhile, Question 2 supporters, largely funded by Unz, undertook a large-scale public relations campaign to convince the Massachusetts electorate that the proposed changes to the state's bilingual education laws would greatly improve the education of non-native English speakers.

On Election Day, the political debate was reduced to two deceptively simple choices. The ballot stated that a 'yes' vote, "would require that, with limited exceptions, all public school children must be taught English by being taught all subjects in English and being placed in English language classrooms." A 'no' vote, "would make no changes in English language education in public schools" (Secretary of the Commonwealth of Massachusetts 2002). In the end, Question 2 passed with 70 percent of the vote, thanks in part to the well-funded efforts of its proponents (Zehr 2002, 22).

Despite the political triumph of the new SEI policy, the state must find a way to translate the policy into practice before any new bilingual classes can be taught and the real effects of the policy change can be known. Implementing such a controversial policy will likely prove difficult. Among the primary factors influencing policy implementation are legitimacy and teacher motivation, which will be examined in turn in the sections that follow.

\section{Policy Implementation and Public Perception}

The effort to transfer bilingual education policies from the political sphere into Massachusetts classrooms will require key stakeholders to collaborate during implementation. One of the primary factors shaping implementation is the perceived legitimacy of the policy, particularly among its potential implementers and targeted populations. In general, perceptions of policy legitimacy develop during the political process when reforms are proposed and approved, and these perceptions continue to affect these policies as they are implemented. To begin examining the perceptions of legitimacy of Massachusetts bilingual education reform, the logical place to start is with the originators of the policy proposal.

The question of bilingual education in Massachusetts became part of the political agenda when a non-Massachusetts citizen, Ron Unz, recruited Lincoln Tamayo and others to lead efforts designed to garner support for SEI programs. Unz and his group, English for the Children, had been successful in California with the passage of Proposition 227 and were looking to make similar changes in Arizona and Colorado. A Silicon Valley millionaire, Unz was widely reported to have spent over $\$ 700,000$ of his own money in support of SEI policy in California (Hornblower 1998, 56). Similarly, he contributed over $\$ 100,000$ to the Massachusetts campaign (Vaishnav 2002, 2). Unz and his supporters not only enjoyed ample funding for their work but they also had a bold spokesperson in current governor Mitt Romney.

Opposing this well-funded and politically powerful group were teachers, immigrant groups, state and national bilingual language associations, and national teachers' organizations. These groups questioned both Unz's credibility and the potential for positive outcomes from SEI. To many SEI opponents, Unz lacked credibility based on his political viewpoints and his lack of public policy experience. In addition, SEI opponents objected to the policy in principle; they doubted the effectiveness of SEI programs. At their annual meeting of delegates, the Massachusetts Teachers Association (MTA) stated in a resolution that:

The MTA believes that children from all cultures should have equal opportunity to a complete education and that each district should provide necessary language acquisition support and resources. MTA opposes any prohibition on teaching students in their native languages. (Massachusetts Teachers Association 2003)

Together, this coalition of educators and Massachusetts citizens opposed the SEI proposal and criticized efforts to move away from native language instruction. 
Not only did the potential primary implementersthe teachers-doubt the legitimacy of the policy but the primary populations intended to benefit from these new programs also were unconvinced. Published shortly after the ballot decision, a study based on exitpolling data across fifteen Massachusetts voting precincts found that 93 percent of the 1,491 people identifying themselves as Latinos had voted no on Question 2 (Capetillo-Ponce 2003). This fact is noteworthy, as the overwhelming majority of students served by Massachusetts' bilingual education programs are Latino.

Further adding fuel to this political fire was the mechanism through which this change occurred. Because these reforms were presented to voters in the form of a ballot initiative, only limited dialogue and debate preceded the November 2002 vote. As a result, teachers were not asked to share their educational expertise and suggestions regarding bilingual education and the recipients of bilingual education services also were not invited to share their perspectives on the issue. Instead, advocates of SEI imposed their perspectives on both teachers and students with little regard for their views.

In response to the apparent credibility gap, lack of evidence supporting SEI practices, and the absence of open and candid discussion about the policy proposal, teachers and bilingual education students both saw SEI policy as illegitimate at the time that it was passed, and these sentiments likely will carry over to affect the implementation process that must follow.

\section{Teacher Motivation and Potential Points OF TENSION}

A second major issue that arises during policy implementation centers around teacher motivation. Based on research on implementation conducted by Malcolm Goggin, the fact that many Massachusetts teachers see the new policies as illegitimate may limit their motivation to implement the changes. In any educational reform process, a myriad of factors can affect the willingness of a teacher to fully and faithfully implement a new policy (1990). In the Massachusetts case, several specific factors likely will influence the motivation of the teachers most directly responsible for carrying out bilingual education reforms.
Research on other similar reforms shows that the existence of a significant disconnect between teacher perspectives and policy realities can contribute to eventual implementation failure. Leithwood notes, in a study in San Diego, that

how the reform was introduced "soured people from believing in the benefits of the 'what', causing teacher resistance, animosity, and angst within some schools". Furthermore, some teachers resisted the initiative because they believed there was insufficient evidence to support the positive effects claimed by the reformers. (Leithwood et al. 2002, 102)

Similar challenges arose in the Massachusetts case. Many Massachusetts teachers were both displeased with the way in which the reform was introduced and were wary about the effectiveness of SEI pedagogy.

Teachers felt that Unz and his supporters swept into Massachusetts and ran what was widely perceived to be an ideological campaign. Both teachers and bilingual community leaders questioned the appropriateness of Unz's involvement and the authenticity of his commitment to improving bilingual education, as he was neither an educator nor a Massachusetts citizen. Moreover, there was a documented lack of evidence and credible research to bolster his supporters' claims of either the failure of existing TBE programs or the potential success of SEI programs. Combined with Unz's previous bilingual education reform efforts and the ideological views he expressed regarding the situation in California, Unz's opponents quickly drew a picture of him as an outsider trying to hijack the political process for personal gain. The negative perceptions of Unz and SEI policies held by teachers during the political process likely will carry over to the implementation phase of the reforms as teachers will lack the motivation to support what they see as an illegitimate policy.

Another source of tension affecting teacher motivation to implement these policy changes may arise in response to a change in governance structure made by the provision. Prior to November 2002, teachers in Massachusetts held substantial discretionary power when it came to hilingual 
education. The guidelines that existed within the law were mostly programmatic requirements related to student/teacher ratio and parent waiver provisions. No stipulations were made regarding pedagogical technique, thus placing curriculum design under the control of classroom teachers rather than in the hands of the state. Further, no enforcement mechanism. existed under the 1971 law. Collectively, these factors gave teachers significant power in determining the course of bilingual education policies in Massachusetts.

The provisions of Question 2 change this system. The new policy is explicit about how much English should be used in bilingual classrooms - as little as possible. Additionally, the balance of control shifts away from the teacher as the new standard requires mainstreaming students into all-English classrooms as soon as possible. Cumulatively, these two provisions largely restrict the teacher's role in shaping a bilingual curriculum and may result in limited teacher support during implementation.

To ensure teacher compliance during implementation, the writers of Question 2 included an enforcement mechanism. In fact, these enforcement provisions were not only new but were particularly harsh. Massachusetts General Law Chapter 71A $\S$ 6(b) states:

Any school district employee... who willfully and repeatedly refuses to implement the terms of this chapter may be held personally liable for reasonable attorney's fees, costs and compensatory damages by the child's parents or legal guardian, and shall not be subsequently indemnified for such monetary judgment by any public or private third party. Any individual found so liable shall be barred from election or reelection to any school committee and from employment in any public school district for a period of five years following the entry of final judgment.

These provisions were so worrisome to teachers that they actually framed the first line of opposition on their ballot comment by stating that, "teachers should focus on teaching kids English, not worrying about being sued for helping a child learn" (Secretary of the Commonwealth of Massachusetts 2002). Now that these proposals are law, it is reasonable to suggest that these negative consequences will induce teachers to act in compliance with the law. However, it should also be noted that if there are avenues by which teachers can avoid such consequences while continuing to teach the way they wish to, full compliance is unlikely.

It can be asserted with great certainty that the sentiments developed during the political process surrounding bilingual education reform in Massachusetts will resurface during implementation. The shift in governance structure, the loss of teacher discretion, and the prospect of harsh sanctions, together with the SEI's supporters' lack of perceived legitimacy, are all likely to adversely affect teacher motivation to faithfully implement these reforms.

\section{Painting A Picture: Lessons from California}

After examining the political path and actual substance of Massachusetts' bilingual education reforms through the lenses of policy legitimacy and teacher motivation, it bears asking how implementation will proceed. Certainly, as these policy changes were only recently mandated, there is a shortage of literature on the actions and reactions of educators during the implementation process. In fact, implementation of bilingual education program changes is not scheduled to take place until the beginning of the 2003-2004 academic year. Still, examination of bilingual education reforms in California may provide insight into the future of bilingual education in Massachusetts.

On June 2, 1998, the state of California passed Proposition 227, the "English for the Children Initiative," by a 61 percent majority (Eugene Garcia 2000). The provisions of this ballot initiative were similar to those on the Massachusetts ballot in 2002 . The political process in California was initiated by Unz, and the coalitions supporting and opposing Proposition 227 also paralleled those in Massachusetts. More importantly, the same concerns now surrounding legitimacy and teacher motivation in Massachusetts were present in California during the policy approval and implementation processes. 
However, while there are clear similarities between California and Massachusetts regarding the political progression of the bilingual issue, it is necessary to note that such a comparison is not perfect. Inevitably, the variability that one finds within states also occurs when comparing states with each other. These differences range from programmatic (the interaction between strictly Californian educational programs) to demographic (a higher percentage of Latino residents in California than in Massachusetts) (American Institute for Research and WestEd 2002, IV-I). Nonetheless, for the purposes of the issues examined here, the differences between the programs and populations of the states of Massachusetts and California are not significant since the implementation of bilingual education programs is conducted by individual school districts, not the state. Moreover, the goals of educating children are the same whether the children live in Massachusetts or California.

Having established that California may be a useful predictor of Massachusetts' implementation of new bilingual education programs, the following are some potential implementation outcomes. While only a few possible outcomes are discussed here, numerous others exist. This discussion focuses on possible outcomes that are directly linked to weak teacher motivation and the perceived lack of policy legitimacy. As such, these outcomes also are among the primary behaviors to which policy makers should pay attention as they work to ensure implementation fidelity.

\section{Implementation Will Be Community Oriented}

Within the first few years of Proposition 227's implementation, it became apparent which school districts in California would be quick to comply and which would not. Not surprisingly, the majority of those districts that reported a smooth transition had small bilingual education programs. One of the primary reasons for delayed implementation in other districts was the time spent discussing the proposed changes with parents and community leaders (Maxwell-Jolly 2000). There were numerous reasons for these discussions. First, educational administrators wished to inform the community about the implications of the changes to the law. Second, after sufficiently explaining the changes and how they might affect the classroom, these administrators presented options that would enable school districts to appropriately fit the policy to their community's needs.

Despite the harsh enforcement provisions that are also part of the California law, teachers sought community input, even if these policy suggestions came close to violating the spirit of the established regulations. In the end, the discussions in these communities yielded policies that were similar to the policies in place before the passage of Proposition 227. In essence, the lack of perceived legitimacy led educators to ignore the changes in the law and formulate solutions appropriate to their school districts.

This community-oriented process may also emerge in Massachusetts. After communities learn about the changes and their effects, local policy decisions will need to be made. It seems reasonable that, like California, Massachusetts school districts in which bilingual education is popular will experience more policy reformulation than those where it is not. In either case, an attempt to balance the demands of the law with the needs of children will occur as educators assess the appropriateness of the new law for their school district and then develop a course of action that will address community concerns.

\section{Schools Will Change Reforms Accordingly}

The motivation to alter reforms does not come from the community alone. For many teachers, a primary motivation for entering the education profession is a desire to develop students' skills and abilities, and each has his or her own feelings about how best to accomplish that goal. When individual goals and motivations of teachers are challenged, the implementation of mandated reforms will inevitably be affected (Cuban 1998). In California, teachers actively advertised and utilized parental waivers (Augustine Garcia 2000). A parental waiver allows a bilingual education student to remain in a bilingual program rather than be mainstreamed into an allEnglish classroom environment. This waiver option has allowed districts to use parental support of traditional bilingual education to justify deviation from SEI policy. Without such waivers, teachers are required by law to transition students into Englishonly classrooms no later than one year after entrance into an SEI program. However, for those teachers who 
firmly believe that SEI pedagogies are not appropriate for their students, parental waivers provide them with the necessary exception to continue teaching as usual.

In Massachusetts, a large increase in the number of parental waivers can be foreseen as well. While it is clear that teachers disagree with the goals and provisions of Question 2, it is hard to know to what ends they are willing to go to oppose its requirements, particularly in light of the harsh enforcement mechanisms in place. The practice of actively endorsing waivers empowers communities to modify SEI policies to more effectively meet perceived needs. Should the waiver approach be taken, interested communities can effectively render these new provisions moot. This possibility certainly remains in Massachusetts.

\section{Policies Will Continue to Change}

Even as local communities and teachers continue to question the legitimacy of mandated reforms and their impact on students, political decision makers are apt to do the same. It is merely a question of time and political climate before legislators once again choose to re-evaluate bilingual education policy. In fact, this has already happened in Massachusetts. Massachusetts bilingual education law has already been amended to exempt two-way bilingual education programs, which offer linguistic and academic training in English for half of the school day and instruction in another language for the remainder of the day, from the new provisions to implement SEI (Lewis and Kurtz $2003,1)$. Though some legislators were hesitant to overrule a popular mandate and were unwilling to antagonize a veto-threatening governor, these changes eventually passed by a slim margin when the legislature overrode Governor Romney's veto.

Clearly, to use the words of Goggin, the necessary "situational capacity" existed in order to spur legislative action aimed at loosening the new standards (1990). In many ways, this reaction by the legislature merely reflects Massachusetts' traditionally liberalleaning political orientation. This amendment of the new law was also made easier because many of the constituencies that helped to pass Question 2 in the first place were not consulted or involved.

However, the winds of change may not be at gale force. Though Governor Romney was forced to relent by the legislature, his harsh public criticism of the legislature's attempt at undoing "the will of the People" may start a fight that legislators currently do not have an interest in pursuing (Vaishnav 2003, 2). Thus far, his efforts have stemmed the tides of change as all proposals to further dilute the effectiveness of Question 2 have stalled in the legislature and will likely remain so until after the 2004 election.

\section{Moving the Process Along: Possibilities FOR IMPROVING IMPLEMENTATION}

Clearly, the projected course of implementation in Massachusetts highlights the outstanding issues surrounding perceived policy legitimacy and teacher motivation. First and foremost, because there is still no consensus on the presence or nature of Massachusetts' perceived bilingual education deficiency, communities and teachers are likely to take matters into their own hands by altering policies to meet perceived needs. For teachers, there is little motivation to change their teaching practices or undergo new training to meet newly mandated requirements. Finally, even if it becomes widely accepted that the new reforms need to be altered, many stakeholders would be hesitant to reenter a political process that betrayed them in the first place.

\section{Strengthen Data-Recording Requirements}

As was mentioned earlier, no comprehensive data regarding Massachusetts' bilingual education programs exist, which creates several problems for researchers working to evaluate bilingual education programs and for political players attempting to justify program reforms. Unfortunately, data recording provisions were not included in the Question 2 provisions. In order to understand the true nature of the issue and thus grant legitimacy to any prescribed reforms, Massachusetts needs to design data collection systems that will not be too burdensome on teachers yet will provide comprehensive data for researchers. As no current infrastructure exists for bilingual education data-keeping in Massachusetts, a logical first step toward this goal would be to link such data collection practices and systems to the federal No Child Left Behind Act, which does include some datarecording requirements. 
Once a sufficient amount of data has been collected, more comprehensive studies need to be conducted to examine program effectiveness. Data on students' language ability and subject matter proficiency, together with bilingual educational program history, could be vitally important in evaluating the impact of these programs. To date, the debate about bilingual education in Massachusetts has not been evidence-based, a condition that has merely fed the widespread skepticism of bilingual educators and their students and families. Enhanced data collection capabilities and methodologically rigorous program evaluation would allow for the effective analysis of such policies in Massachusetts, thus enabling school districts and policy makers to make informed and publicly credible decisions about bilingual education policy.

\section{Teacher Training Should Be Funded}

When both California and Massachusetts passed their respective ballot initiatives changing bilingual education law, new teacher training standards were mandated as well. In Massachusetts, the reform measure stipulates that teachers in new SEI classrooms must be certified and receive training in second language acquisition. Such training necessarily requires substantial funding. However, the Massachusetts measure does not appropriate such funds. This places an additional burden of funding on local school districts or teachers who may already be unmotivated to implement these bilingual reforms in the first place.

If it is indeed the goal of Question 2 supporters and legislators to implement fully the new bilingual education provisions, the teachers who will be charged with implementing the reforms must be trained to do so effectively. Additionally, as the training of new teachers progresses or as policies change, needs assessments should be conducted regularly to ensure that sufficient training funds are available. While mandates are often viewed by teachers with suspicion and perhaps even contempt, providing teachers with the ability to meet these new standards can go a long way toward building trust in the policy and increasing teacher motivation.

\section{Move Toward Consensus-Building}

Certainly, of the three suggestions made, this is by nature the most difficult to achieve. Since much of the current tension around bilingual education is the product of a contentious political process that resulted in a law that is unpopular with teachers, consensusbuilding efforts would seem to be a logical first step toward improving the implementation process. It is clear that the policy-making process has not ended for bilingual education in Massachusetts as numerous parties are not satisfied with the law passed in 2002. Perhaps more fundamentally, because of what transpired and the manner in which reform was achieved, implementing the final product will prove to be exceptionally difficult. Logically, steps must be taken to support the consensus-building process before meaningful reform can occur.

Education researchers Paul Hill and Mary Cielo offer a snapshot of what consensus-building may look like. They conclude that to minimize the effects of contentious politics on policy implementation, educational administrators and teachers must be involved in the policy formulation process (Hill and Cielo 1998). Such a strategy would avoid the us versus them perception that characterized the Question 2 process. Furthermore, this concerted involvement of affected parties and educational experts generates a sense of commitment and a foundation of legitimacy in the policy reform. Though such a process would inevitably be fraught with numerous chailenges, its outcomes could provide policy stability, meet community needs, and engender teacher motivation.

Preliminary reports indicate that initial steps are being taken to build this consensus. Currently, efforts are being made to mend ties between several local school districts and the several education boards and commissions appointed by the governor. For example, the City of Framingham has been working with the state board of education to tailor reforms addressing the needs of Framingham's high minority student population while remaining within the requirements of the law (Massachusetts Teachers Association 2004). Support for these reforms is strong among Framingham's professional teaching staff and the parents. While there is no guarantee that this process will continue to be supported by Framingham or other communities, initial efforts at dialogue are occurring 
and should be taken as a positive sign of progress toward consensus-building. Should this progress continue, the perceived legitimacy of any policy prescription will be greatly increased and would lead to enhanced motivation on the part of teachers as they are asked to implement such changes.

\section{Conclusion}

This article has focused on the difficulty that can arise in implementing a policy that lacks perceived legitimacy and a motivated work force. Such a situation exists currently in Massachusetts and unless some form of intervention occurs, the effective implementation of new bilingual education provisions is in jeopardy. Because the parents of children receiving bilingual education sharply disagree with the motives behind and provisions enforcing the new laws, there is little community support for implementing them. Teachers, facing increased sanctions, the loss of pedagogical control, and the prospect of unfunded training requirements, also have valid reasons to be frustrated with the new situation in the post-Question 2 world.

Together, the dissatisfaction of these two groups presents a formidable obstacle to implementation progress. Should this process proceed without adjustment, it is apparent from initial indications in Massachusetts (and from the lessons learned in California) that reforms will proceed in a climate of antagonism and hostility. In the case of Massachusetts, this will mean that parents and teachers together will seek to exploit any weaknesses within the new law to achieve what they perceive to be in the best interests of their children.

This said, it should also be noted that the effects of these reforms will vary depending on the specifics of the community in question. Factors such as the feelings of parents and teachers, the total number of bilingual students, and the budgetary capacity of a specific community will require individualized responses. Finally, it is important to point out that while there are numerous hurdles on the path toward smooth implementation of the changes called for in Question 2, a number of possible solutions exist as well.

Despite a rousing victory for supporters of a ballot initiative calling for drastic changes to bilingual education law, the prospect that these legal changes will become a reality are murky at best. Faced with substantial obstacles such as a lack of teacher motivation and the lingering bitterness of a contentious political battle, implementation will inevitably be a struggle. If teachers and parents unite to defeat the implementation of the new law, the original winners of the "zero-sum" political game could in fact become its biggest losers. However, as this article makes clear, there are avenues that can be followed in which all parties can win by effectively implementing sensible reforms.

\section{REFERENCES}

American Institutes for Research and WestEd. 2002. Effects of the Implementation of Proposition 227 on the Education of English Learners, K-12: Year 2Report.http://www.air.org/pubs/ Year2FinalRpt.pdf.

Capetillo-Ponce, Jorge. 2003. The Vote on Bilingual Education and Latino Identity in Massachusetts. Working Paper, University of Massachusetts-Boston.

Cuban, Larry. 1998. How Schools Change Reforms: Redefining Reform Success and Failure. Teachers College Record 99(3): 453-477.

Garcia, Augustine. 2000. Informed Parent Consent and Proposition 227. Bilingual Research Journal 24: $1 \& 2$.

Garcia, Eugene E. 2000. Implementation of California's Proposition 227: 1998-2000. Bilingual Research Journal 24: 1\&2.

Goggin, Malcolm L., Ann O'M. Bowman, James P. Lester and Laurence O'Toole. 1990. Implementation Theory and Practice: Toward a Third Generation. New York: Harper Collins.

Hill, Paul T. and Mary B. Cielo. 1998. Creating Reforms That Can Work. In Fixing Urban Schools, 61-84. Washington, D.C.: Brookings Institution Press. 
Hornblower, Margot. 1998. The Man Behind Proposition 227. Time Magazine, June 8.

Leithwood, Kenneth, Rosanne Steinback and Doris Jantzi. 2002. School Leadership and Teachers' Motivation to Implement Accountability Policies. Educational Administration Quarterly 38(1): 94119.

Lipsky, Michael. 1980. Street-Level Bureaucracy: The Critical Role of Street-Level Bureaucrats. In Classics of Public Administration, ed. Jay M. Shafritz and Albert C. Hyde, 401. Fort Worth, Texas: Harcourt Brace.

Lewis, Raphael and Michelle Kurtz. 2003. Legislature Loosens Law on English Immersion. The Boston Globe, July 15.

Massachusetts Bilingual Education Commission. 1993. Striving for Success. http:// www.pioneerinstitute.org/research/piopaper/ summ10.cfm.

Massachusetts Board of Education. 2003. Massachusetts Board of Education 2002 Annual Report. Malden, MA: Massachusetts Department of Education.

Massachusetts Teachers Association. 2004. Phone Interview with Ms. Julia Johnson, Governmental Lobbyist. February 11.

- 2003. Resolution of the MTA Annual Meeting of Delegates. http://www.massteacher.org/issues/ bilingual/index.cfin.

Maxwell-Jolly, Julie. 2000. Factors Influencing Implementation of Mandated Policy Change: Proposition 227 in Seven Northern California School Districts. Bilingual Research Journal 24: 1\&2.

Mitchell, Douglas E., Tom Destino, Rita T. Karam, and Anaida Colon-Muniz. 1999. The Politics of Bilingual Education. Educational Policy 13: 86103.

Office of the Attorney General of the Commonwealth of Massachusetts. 2001. An Initiative Petition For A Law: An Act relative to the teaching of English in Public Schools. Boston, Massachusetts: Office of the Attorney General.
Rossell, Christine. 1996. Bilingual Education in Massachusetts: The Emperor Has No Clothes. http:// www.pioneerinstitute.org/research/piopaper/ summ10.cfm.

Secretary of the Commonwealth of Massachusetts. 2002. Information for Voters: The 2002 Ballot Questions. Boston, Massachusetts: Secretary of the Commonwealth.

Vaishnav, Anand. 2003. Firm on English Timetable. The Boston Globe, January 24

2002. Bilingual Education Foes Detail Funding. The Boston Globe, September 7.

Zehr, Mary A. 2002. Colorado Extends Bilingual Education, But Massachusetts Voters Reject It. Education Week 22(6): 22. 
